\title{
Laparoscopic surgery for diverticular colovesical fistula: Single-center experience of 11 cases
}

Daichi Kitaguchi ( $\nabla$ s1930442@s.tsukuba.ac.jp )

Tsukuba Daigaku https://orcid.org/0000-0002-8197-6317

Tsuyoshi Enomoto

Tsukuba Daigaku

\section{Yusuke Ohara}

Tsukuba Daigaku

Yohei Owada

Tsukuba Daigaku

Katsuji Hisakura

Tsukuba Daigaku

Yoshimasa Akashi

Tsukuba Daigaku

Kazuhiro Takahashi

Tsukuba Daigaku

Koichi Ogawa

Tsukuba Daigaku

Osamu Shimomura

Tsukuba Daigaku

Tatsuya Oda

Tsukuba Daigaku

\section{Research note}

Keywords: Colovesical fistula, Diverticular fistula, Laparoscopic surgery, Conversion to open surgery

Posted Date: February 21st, 2020

DOI: https://doi.org/10.21203/rs.2.24207/v1

License: (a) (i) This work is licensed under a Creative Commons Attribution 4.0 International License. Read Full License 
Version of Record: A version of this preprint was published at BMC Research Notes on March 24th, 2020. See the published version at https://doi.org/10.1186/s13104-020-05022-4. 


\section{Abstract}

Objective: Laparoscopic surgery for diverticular colovesical fistula (CVF) is technically challenging, and the incidence of conversion to open surgery (COS) is high. The aims of this study were to review our experience with laparoscopic surgery for diverticular CVF and to identify preoperative risk factors for COS.

Results: This was a single institution, retrospective, observational study of 11 patients who had undergone laparoscopic sigmoid colon resection with fistula resection for diverticular CVF from 2014 to 2019. Preoperative magnetic resonance imaging (MRI) was utilized to evaluate fistula location in the bladder, patency of the rectovesical pouch, and estimated contact area between the sigmoid colon and bladder. The relationship between preoperative variables and incidence of COS was analyzed between completed laparoscopy and COS groups. The overall incidence of postoperative morbidity (ClavienDindo classification Grade II or higher) was 36\% (4/11). Severe morbidity, reoperation, and mortality were not observed. The incidence of COS was $27 \%(3 / 11)$. Posterior bladder fistulas were significantly associated with $\operatorname{COS}(p=0.006)$. CVFs located on the posterior bladder appears to be a risk factor for COS. Identifying the risk factors for COS preoperatively could help guide the intraoperative course.

\section{Introduction}

Fistulae complicate approximately $20 \%$ of colonic diverticulitis cases, and most commonly involve the bladder (65-69\%) [1]. Diverticular colovesical fistulae (CVF) seldom close spontaneously and cause various sequelae, including recurrent urinary tract infections (UTI), cystitis, pyelonephritis, urinary sepsis, and renal impairment. Therefore, operative management is the recommended treatment for CVF [2-10].

Several retrospective case series have suggested both the safety and feasibility of laparoscopic management of diverticular CVF in a highly selected patient-group. Laparoscopic treatment results in earlier return of bowel function and shorter hospitalization time with low overall morbidity $[9,11-13]$. However, laparoscopic surgery for diverticular CVF is still technically challenging because of extensive inflammation and abscess formation. These complications may explain why the incidence of conversion to open surgery (COS) ranges from 0 to $50 \%$ [9,11-20]. Identification of preoperative risk factors for COS is critical, as evaluating risk can help guide the decision on conversion during the surgery. Knowing risk in advance allows surgeons to determine whether open surgery should be the initial approach, thereby avoiding the potential complications that may lead to intraoperative COS. Furthermore, awareness of these risk factors allows for more thorough briefings of the patients, allowing them to be better-informed before giving consent.

The aims of this study were to review our experience with laparoscopic surgery for diverticular CVF and to identify preoperative risk factors for COS by comparing completed laparoscopy and COS groups.

\section{Methods}




\section{Demographics}

All patients who had undergone laparoscopic sigmoid colon resection with fistula resection for diverticular CVF from 2014 to 2019 were identified in our prospective, single-center institutional database. Emergent cases were not included.

All patients had undergone preoperative colonoscopy, computed tomography, and magnetic resonance imaging (MRI) to confirm CVF and eliminate the possibility of colon cancer. Cystoscopy was also performed on all patients to confirm patency of both ureteral orifices and exclude urological malignancy.

Patient data were collected through electronic medical record systems. Data included information on age, sex, body mass index (BMI), previous abdominal operations, American Society of Anesthesiologists physical status (ASA-PS) classification, and preoperative hematological inflammatory findings including white blood cells (WBCs) and C-reactive protein (CRP).

Preoperative MRI was evaluated for the following features: location of the fistula on the bladder, patency of the rectovesical pouch, and estimated contact area (eCA) between the sigmoid colon and bladder. eCA was calculated as the product of the length and width between the sigmoid colon and bladder on twodimensional MRI images (Fig. 1). Intraoperative measurements of interest included operative time, blood loss, rate of positive bladder leak tests, type of bladder repair, stoma creation, complications, and COS. Postoperative measurements of interest included morbidity, timing of Foley catheter removal, length of hospital stay, reoperation, and mortality. The Foley catheter was removed on postoperative day 7; however, the schedule was moved forward if the patients demanded it and was delayed when there was concern about leakage.

Written informed consent was obtained preoperatively from all patients. The protocol for this retrospective study was approved by the ethics committee of the University of Tsukuba Hospital (registration No. R01-271). The study conforms to the provisions of the Declaration of Helsinki in 1964 (as revised in Brazil in 2013).

\section{Operative Technique}

Laparoscopy was performed using five ports. First, the sigmoid colon was detached from the bladder using electrocautery. The left ureter, gonadal vessels, inferior mesenteric plexus, and superior hypogastric plexus were identified and preserved. In patients with severe inflammation, left or bilateral ureter stents were inserted to facilitate ureter identification. Fistula resection was performed followed by sigmoid colon resection in a standard manner. Rectal transection was performed with a linear stapler, and the specimen was extracted through the navel port. Anastomoses were performed with a circular stapler, and a bladder leak test was routinely performed. When the results were positive, repair of the bladder wall was performed. When the results were negative, it was deemed to be unnecessary.

\section{Statistical Analysis}


Quantitative data were reported as median (range) and compared using the Mann-Whitney U test. Qualitative data were reported as the number of patients (percentage) using Fisher's exact test. All tests performed were two-tailed with the level of significance set at $p<0.05$. All statistical analyses were carried out using EZR (Saitama Medical Center, Jichi Medical University, Saitama, Japan), a graphical user interface for R (The R Foundation for Statistical Computing, Vienna, Austria). EZR is a modified version of $\mathrm{R}$ commander designed for statistical functions frequently used in biostatistics [21]. We used statistics in a descriptive fashion realizing that with the number of subjects, no robust statistical analysis was possible.

\section{Results}

During the study period, eleven patients underwent laparoscopic sigmoid colon resection with fistula resection for diverticular CVF. The patient characteristics are described in Table 1. The median age of the cohort was 55 years (29-73), and 91\% (10/11) of patients were male. The median BMI was $24 \mathrm{~kg} / \mathrm{m}^{2}$ $\left(20-29 \mathrm{~kg} / \mathrm{m}^{2}\right)$, and the majority of patients were of ASA-PS class 2 or 3 (total $\left.82 \%, 9 / 11\right)$. None of the patients had undergone previous abdominal operations. Regarding preoperative laboratory findings, the median WBC was $6900 / \mu \mathrm{L}(4300-14000 / \mu \mathrm{L})$ and the median CRP was $0.64 \mathrm{mg} / \mathrm{dL}(<0.03-$ $3.93 \mathrm{mg} / \mathrm{dL}$ ). The preoperative MRI studies showed that the majority of fistulas were located on the bladder's superior surface $(73 \%, 8 / 11)$ rather than the posterior surface. Patency of rectovesical pouch was observed in $55 \%(6 / 11)$ of patients, and the median eCA was $450 \mathrm{~mm}^{2}\left(100-1575 \mathrm{~mm}^{2}\right)$. 
Table 1

Patient characteristics, intraoperative outcomes, and postoperative outcomes

\begin{tabular}{|c|c|c|}
\hline & & $N=11$ \\
\hline Age (years) & & $55[29-73]^{*}$ \\
\hline Sex (male) & & $10(91 \%)$ \\
\hline $\mathrm{BMI}\left(\mathrm{kg} / \mathrm{m}^{2}\right)$ & & $24[20-29]^{*}$ \\
\hline ASA-PS & $\begin{array}{l}1 \\
2 \\
3\end{array}$ & $\begin{array}{l}2(18 \%) \\
5(45 \%) \\
4(36 \%)\end{array}$ \\
\hline Prior abdominal operations & & 0 \\
\hline Preoperative blood exams & $\begin{array}{l}\operatorname{WBC}(/ \mu \mathrm{l}) \\
\operatorname{CRP}(\mathrm{mg} / \mathrm{dl})\end{array}$ & $\begin{array}{l}6900[4300-14000]^{\star} \\
0.64[<0.03-3.93]^{\star}\end{array}$ \\
\hline Operative time (min) & & $251[207-385]^{\star}$ \\
\hline Blood loss (ml) & & $100[0-560]^{*}$ \\
\hline Bladder leak test (positive) & & $4(57 \%)$ \\
\hline Type of bladder repair & $\begin{array}{l}\text { Simple closure } \\
\text { Partial resection } \\
\text { No repair }\end{array}$ & $\begin{array}{l}6(55 \%) \\
0 \\
5(45 \%)\end{array}$ \\
\hline Stoma creation & & 0 \\
\hline Complication & & 0 \\
\hline Conversion to open surgery & & $3(27 \%)$ \\
\hline $\begin{array}{l}\text { Overall morbidity } \\
\text { (Clavien-Dindo Grade } 2 \text { or more) }\end{array}$ & $\begin{array}{l}\text { UTI } \\
\text { lleus } \\
\text { Rest abscess }\end{array}$ & $\begin{array}{l}4(36 \%) \\
2 \\
1 \\
1\end{array}$ \\
\hline Timing of Foley catheter removal (POD) & & $7[3-11]^{\star}$ \\
\hline Length of hospital stay (days) & & $13[8-21] *$ \\
\hline Reoperation & & 0 \\
\hline Mortality & & 0 \\
\hline \multicolumn{3}{|l|}{ (*Median [range]) } \\
\hline $\begin{array}{l}\text { BMI: body mass index; ASA-PS: America } \\
\text { blood cell; CRP: C-reactive protein; UTI: u }\end{array}$ & $\begin{array}{l}\text { Anesthesiologis } \\
\text { nfection; POD: } p\end{array}$ & $\begin{array}{l}\text { sical status; WBC: white } \\
\text { erative day }\end{array}$ \\
\hline
\end{tabular}

\section{Intraoperative and Postoperative Outcomes}


The median operative time was $251 \mathrm{~min}$ (207-385 min), and median blood loss was $100 \mathrm{~mL}$ (0$560 \mathrm{~mL}$ ). Simple closure without partial resection of the bladder wall was performed in six patients (55\%) with a positive bladder leak test. No intraoperative complications occurred, and no stomas were required. The overall incidence of COS was $27 \%$ (3/11 patients) (Table 1 ).

The overall incidence of postoperative morbidity (Clavien-Dindo classification Grade Il or higher) was $36 \%$ (4/11 patients). UTIs occurred in two patients, and ileus and rest abscess occurred in one each. The median timing of Foley catheter removal was postoperative day 7 (range of 3-11), and the median hospital stay was 13 days (range of 8-21). No reoperations or mortalities occurred (Table 1).

\section{Preoperative Risk Factors for COS}

The relationship between each variable and the incidence of COS is summarized in Table 2. Regarding the influence of fistula location, posterior bladder fistulas were significantly associated with COS while superior fistulas were not $(3 / 3(100 \%)$ vs. $0 / 8(0 \%) ; p=0.006)$. Age, sex, BMI, preoperative laboratory, and the other MRI findings were not associated with COS.

Table 2

Relationship between preoperative variables and conversion to open surgery

\begin{tabular}{|c|c|c|c|c|c|}
\hline & & $\mathbf{N}$ & $\cos$ & $\mathrm{OR}[95 \% \mathrm{Cl}]$ & P-value* \\
\hline Age (years) & $\begin{array}{l}<60 \\
60 \leqq\end{array}$ & $\begin{array}{l}6 \\
5\end{array}$ & $\begin{array}{l}1(17 \%) \\
2(40 \%)\end{array}$ & $\begin{array}{l}2.97 \\
{[0.11-235]}\end{array}$ & 0.545 \\
\hline Sex & $\begin{array}{l}\text { Male } \\
\text { Female }\end{array}$ & $\begin{array}{l}10 \\
1\end{array}$ & $\begin{array}{l}3(30 \%) \\
0\end{array}$ & $\begin{array}{l}0 \\
{[0-104]}\end{array}$ & 1 \\
\hline BMI $\left(\mathrm{kg} / \mathrm{m}^{2}\right)$ & $\begin{array}{l}<25 \\
25<\end{array}$ & $\begin{array}{l}7 \\
4\end{array}$ & $\begin{array}{l}3(43 \%) \\
0\end{array}$ & $\begin{array}{l}0 \\
{[0-4.16]}\end{array}$ & 0.236 \\
\hline WBC $(/ \mu l)$ & $\begin{array}{l}<8000 \\
8000<\end{array}$ & $\begin{array}{l}6 \\
5\end{array}$ & $\begin{array}{l}2(33 \%) \\
1(20 \%)\end{array}$ & $\begin{array}{l}0.53 \\
{[0.007-14.5]}\end{array}$ & 0.532 \\
\hline $\operatorname{CRP}(\mathrm{mg} / \mathrm{dl})$ & $\begin{array}{l}<1.0 \\
1.0<\end{array}$ & $\begin{array}{l}8 \\
3\end{array}$ & $\begin{array}{l}3(38 \%) \\
0\end{array}$ & $\begin{array}{l}0 \\
{[0-7.13]}\end{array}$ & 0.491 \\
\hline Fistula location on bladder & $\begin{array}{l}\text { Superior } \\
\text { Posterior }\end{array}$ & $\begin{array}{l}8 \\
3\end{array}$ & $\begin{array}{l}0 \\
3 \\
(100 \%)\end{array}$ & NA & 0.006 \\
\hline Patency of rectovesical pouch & $\begin{array}{l}\text { Yes } \\
\text { No }\end{array}$ & $\begin{array}{l}6 \\
5\end{array}$ & $\begin{array}{l}0 \\
3(60 \%)\end{array}$ & NA & 0.06 \\
\hline $\mathrm{eCA}\left(\mathrm{mm}^{2}\right)$ & $\begin{array}{l}<500 \\
500 \leq\end{array}$ & $\begin{array}{l}6 \\
5\end{array}$ & $\begin{array}{l}0 \\
3(60 \%)\end{array}$ & NA & 0.06 \\
\hline \multicolumn{6}{|l|}{ *Fisher's exact test } \\
\hline $\begin{array}{l}\text { COS: conversion to open surge } \\
\text { white blood cell; CRP: C-reacti } \\
\text { bladder; NA: not available }\end{array}$ & $\begin{array}{l}\text { odds rati } \\
\text { ein; eCA: }\end{array}$ & l: $c 0$ & $\begin{array}{l}\text { dential int } \\
\text { contact ar }\end{array}$ & $\begin{array}{l}\text { l; BMI: body ma } \\
\text { etween sigmoi }\end{array}$ & $\begin{array}{l}\text { index; WBC } \\
\text { lon and }\end{array}$ \\
\hline
\end{tabular}




\section{Discussion}

We reviewed our experience with laparoscopic surgery for diverticular CVF. In our cohort, no severe morbidities or mortalities were observed. The incidence of COS was as high as $27 \%$, and a posterior bladder fistula location was a statistically significant risk factor.

Previous studies have shown that a laparoscopic colectomy can be safely utilized for complicated diverticulitis; however, most reports were limited by exceedingly small cohorts and highly selected patients $[11,14-16]$. In a recent large study of 111 consecutive diverticular fistula cases with minimal exclusion, reported by Martinolich et al. [22], the overall incidence of postoperative complications was $26.4 \%$. In our study, although the overall incidence of postoperative morbidity was as high as $36 \%$, all were no higher than Grade II of the Clavien-Dindo classification for severe complications. Based on these results, it could be concluded that laparoscopic surgery for diverticular CVF is safe and feasible.

Several small retrospective studies on diverticular fistulas have reported that the incidence of COS ranges from 0 to $50 \%,[9,11-20]$ and patients with a preoperative diagnosis of CVF were most likely to require COS. Recent studies on CVF by Badic et al. [14] and Martinolich et al. [22] reported COS incidence rates of $43 \%$ and $42 \%$, respectively, comparable to our rate of $27 \%$. During laparoscopic surgery in general, previously reported risk factors for COS included old age, male sex, high BMI, and previous abdominal operations [23-25]. Diverticular fistula cases, in particular, showed severe inflammation or dense fibrosis impeding safe dissection or ureteral visualization to be the most frequent reason for COS [22]. In our study, although age, BMI, and previous abdominal operations were not significantly correlated with COS, this may simply be a consequence of the small sample size. We proposed three novel MRI features as preoperative risk factors for COS, finding that fistula location on the bladder correlated with COS. Although patency of the rectovesical pouch and eCA did not correlate with COS in this study, this may also be due to the small sample size. It will be necessary to identify more cases and further investigate this topic.

As described by Engledowe et al. [12], small fistulas with accompanying inflammation of the bladder wall were not formally closed, and the Foley catheter was left in place for decompression for 5-7 postoperative days. There were no complications related to urinary leakage in these patients. In our study, bladder wall repair was not performed in patients with a negative leak test, and simple closure without partial resection was sufficient, regardless of the leak test outcome. As a result, no postoperative urinary leakages were observed in our cohort.

Although the decision on COS in the operating room can be subjective and dependent on individual surgeon skill, identifying objective preoperative risk factors associated with COS can provide a lower threshold for proceeding with the potentially inevitable open approach and can catalyze the decision on earlier COS. Furthermore, the ability to identify patients at a high risk of COS can aid surgeons in selecting those who may benefit from primary open surgery, thereby potentially reducing operative time, morbidity, and costs [25]. 


\section{Conclusions}

Laparoscopic surgery for diverticular CVF was safe, despite the high incidence of COS. In addition, CVFs located on the posterior bladder were risk factors for COS. Finally, understanding risk factors for COS preoperatively could be important to guide the operative course.

\section{Limitation}

The current study has several limitations. First, it was a retrospective, single-center analysis of clinical records. Second, because the overall sample size was very small, the accuracy of our outcome analyses were limited, and we considered that it is statistically inappropriate to perform a multivariate analysis.

\section{Abbreviations}

CVF

colovesical fistula

cos

conversion to open surgery

MRI

magnetic resonance imaging

UTI

urinary tract infections

BMI

body mass index

ASA-PS

American Society of Anesthesiologists physical status

WBC

white blood cell

CRP

C-reactive protein

eCA

estimated contact area

\section{Declarations}

\section{Ethics approval and consent to participate}

Written informed consent was preoperatively obtained from all patients. The protocol for this prospective observational study was approved by the ethics committee of the University of Tsukuba Hospital (registration No. R01-271). The study conforms to the provisions of the Declaration of Helsinki in 1964 (as revised in Brazil in 2013). 


\section{Consent for publication}

Written informed consent was including to publish the findings.

\section{Availability of data and materials}

The datasets used and/or analyzed during the current study are available from the corresponding author on reasonable request.

\section{Competing interests}

The authors declare that they have no competing interests.

\section{Funding}

Only institutional sources were used for this study.

\section{Authors' contributions}

All authors contributed to the study conception and design. Material preparation, data collection and analysis were performed by DK, TE, YO, YO, KH, YA, KT, KO, OS, and TO. The first draft of the manuscript was written by DK and all authors commented on previous versions of the manuscript. All authors read and approved the final manuscript.

\section{Acknowledgements}

Not applicable.

\section{References}

1. Woods RJ, Lavery IC, Fazio VW, Jagelman DG, Weakley FL. Internal fistulas in diverticular disease. Dis Colon Rectum. 1988;31:591-6.

2. Scozzari G, Arezzo A, Morino M. Enterovesical fistulas: diagnosis and management. Tech Coloproctol. 2010;14:293-300.

3. Garcea G, Majid I, Sutton CD, Pattenden CJ, Thomas WM. Diagnosis and management of colovesical fistulae; six-year experience of 90 consecutive cases. Colorectal Dis. 2006;8:347-52.

4. Daniels IR, Bekdash B, Scott HJ, Marks CG, Donaldson DR. Diagnostic lessons learnt from a series of enterovesical fistulae. Colorectal Dis. 2002;4:459-62. 
5. Golabek T, Szymanska A, Szopinski T, Bukowczan J, Furmanek M, Powroznik J, Chlosta P. Enterovesical fistulae: aetiology, imaging, and management. Gastroenterol Res Pract. 2013;2013:617967.

6. Kavanagh D, Neary P, Dodd JD, Sheahan KM, O'Donoghue D, Hyland JM. Diagnosis and treatment of enterovesical fistulae. Colorectal Dis. 2005;7:286-91.

7. Lynn ET, Ranasinghe NE, Dallas KB, Divino CM. Management and outcomes of colovesical fistula repair. Am Surg. 2012;78:514-8.

8. De Moya MA, Zacharias N, Osbourne A, Butt MU, Alam HB, King DR, McGovern F, Velmahos GC. Colovesical fistula repair: is early Foley catheter removal safe? J Surg Res. 2009;156:274-7.

9. Cirocchi R, Cochetti G, Randolph J, Listorti C, Castellani E, Renzi C, Mearini E, Fingerhut A. Laparoscopic treatment of colovesical fistulas due to complicated colonic diverticular disease: a systematic review. Tech Coloproctol. 2014;18:873-85.

10. Ferguson GG, Lee EW, Hunt SR, Ridley $\mathrm{CH}$, Brandes SB. Management of the bladder during surgical treatment of enterovesical fistulas from benign bowel disease. J Am Coll Surg. 2008;207:569-72.

11. Cirocchi R, Arezzo A, Renzi C, Cochetti G, D'Andrea V, Fingerhut A, Mearini E, Binda GA. Is laparoscopic surgery the best treatment in fistulas complicating diverticular disease of the sigmoid colon? A systematic review. Int J Surg. 2015;24:95-100.

12. Engledow AH, Pakzad F, Ward NJ, Arulampalam T, Motson RW. Laparoscopic resection of diverticular fistulae: a 10-year experience. Colorectal Dis. 2007;9:632-4.

13. Maciel V, Lujan HJ, Plasencia G, Zeichen M, Mata W, Jorge I, Lee D, Viamonte M 3rd, Hartmann RF. Diverticular disease complicated with colovesical fistula: laparoscopic versus robotic management. Int Surg. 2014;99:203-10.

14. Badic B, Leroux G, Thereaux J, Joumond A, Gancel CH, Bail JP, Meurette G. Colovesical fistula complicating diverticular disease: a 14-year experience. Surg Laparosc Endosc Percutan Tech. 2017;27:94-7.

15. Bhakta A, Tafen M, Glotzer O, Canete J, Chismark AD, Valerian BT, Stain SC, Lee EC. Laparoscopic sigmoid colectomy for complicated diverticulitis is safe: review of 576 consecutive colectomies. Surg Endosc. 2016;30:1629-34.

16. Laurent SR, Detroz B, Detry O, Degauque C, Honore P, Meurisse M. Laparoscopic sigmoidectomy for fistulized diverticulitis. Dis Colon Rectum. 2005;48:148-52.

17. Klarenbeek BR, Veenhof AA, Bergamaschi R, van der Peet DL, van den Broek WT, de Lange ES, Bemelman WA, Heres P, Lacy AM, Engel AF, Cuesta MA. Laparoscopic sigmoid resection for diverticulitis decreases major morbidity rates: a randomized control trial: short-term results of the Sigma Trial. Ann Surg. 2009;249:39-44.

18. Cirocchi R, Farinella E, Trastulli S, Sciannameo F, Audisio RA. Elective sigmoid colectomy for diverticular disease. Laparoscopic vs open surgery: a systematic review. Colorectal Dis. 2012;14:671-83. 
19. Marcucci T, Giannessi S, Giudici F, Riccadonna S, Gori A, Tonelli F. Management of colovesical and colovaginal diverticular fistulas Our experience and literature reviewed. Ann Ital Chir. 2017;88:55-61.

20. Tomizawa K, Toda S, Tate T, Hanaoka Y, Moriyama J, Matoba S, Kuroyanagi H. Laparoscopic surgery for colovesical fistula associated with sigmoid colon diverticulitis: a review of 39 cases. $J$ Anus Rectum Colon. 2019;3:36-42.

21. Kanda Y. Investigation of the freely available easy-to-use software 'EZR' for medical statistics. Bone Marrow Transplant. 2013;48:452-8.

22. Martinolich J, Croasdale DR, Bhakta AS, Ata A, Chismark AD, Valerian BT, Canete JJ, Lee EC. Laparoscopic surgery for diverticular fistulas: outcomes of 111 consecutive cases at a single institution. J Gastrointest Surg. 2019;23:1015-21.

23. Hu ASY, Menon R, Gunnarsson R, de Costa A. Risk factors for conversion of laparoscopic cholecystectomy to open surgery - A systematic literature review of 30 studies. Am J Surg. 2017;214:920-30.

24. Philip Rothman J, Burcharth J, Pommergaard HC, Viereck S, Rosenberg J. Preoperative risk factors for conversion of laparoscopic cholecystectomy to open surgery - A systematic review and metaanalysis of observational studies. Dig Surg. 2016;33:414-23.

25. Finnerty BM, Wu X, Giambrone GP, Gaber-Baylis LK, Zabih R, Bhat A, Zarnegar R, Pomp A, Fleischut P, Afaneh C. Conversion-to-open in laparoscopic appendectomy: A cohort analysis of risk factors and outcomes. Int J Surg. 2017;40:169-75.

\section{Figures}



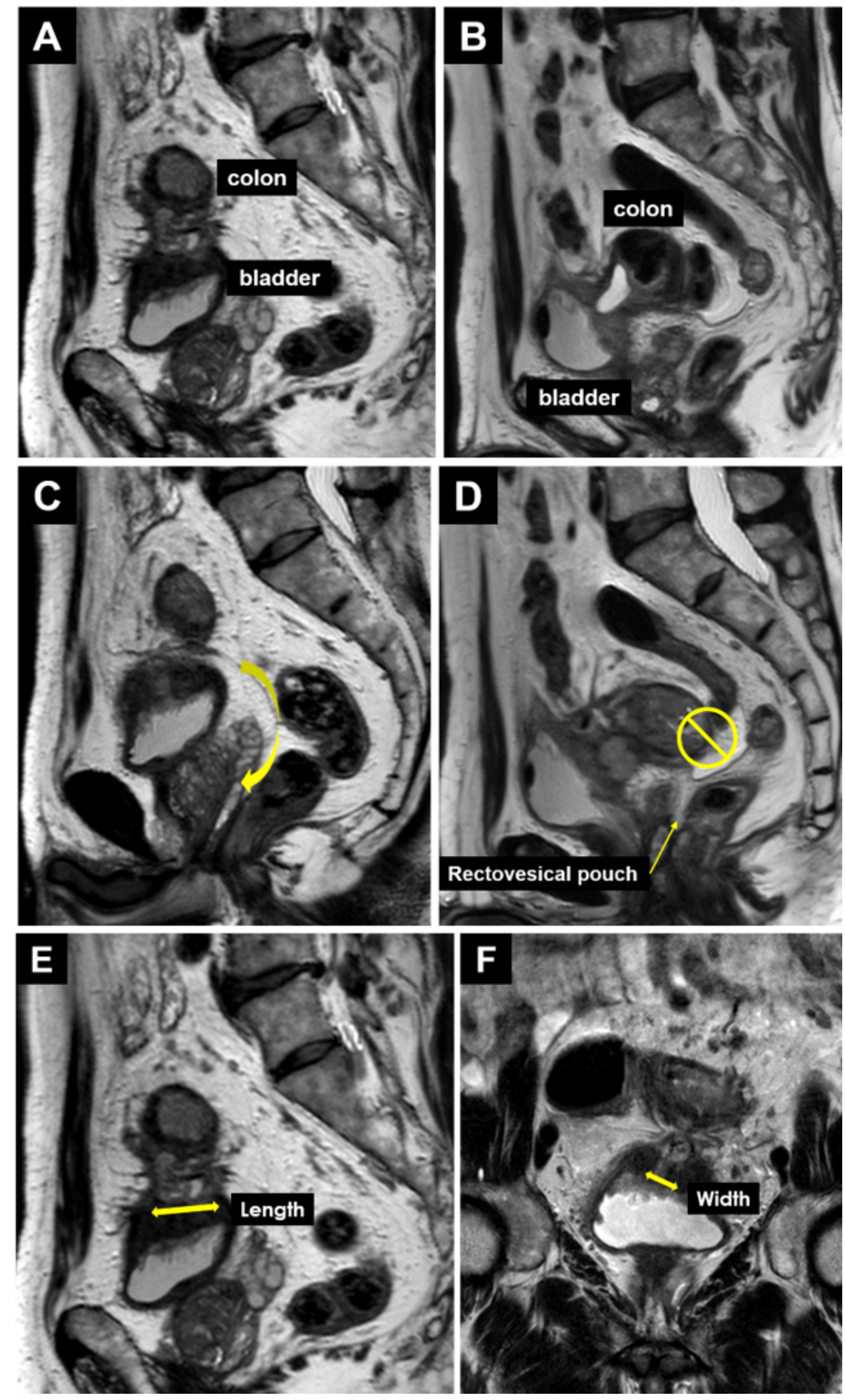

\section{Figure 1}

Fistula location on bladder and patency of the rectovesical pouch were evaluated using preoperative magnetic resonance images (MRI) from a representative case, and the estimated contact area between the sigmoid colon and bladder (eCA) was calculated as the product of the length and width between the sigmoid colon and bladder on two-dimensional MRI. A: Fistula is located on the superior wall of the bladder. B: Fistula is located in the posterior bladder. C: The patency of the rectovesical pouch is 
preserved and the fistula can be encircled. D: The rectovesical pouch is closed and cannot be approached directly. E: Length between the sigmoid colon and bladder on sagittal view. F: Width between the sigmoid colon and bladder on coronal view. 